\title{
MiR-301a Mediates the Effect of IL-6 on the AKT/GSK Pathway and Hepatic Glycogenesis by Regulating PTEN Expression
}

\author{
Lin Dou ${ }^{\mathrm{a}}$ Shuyue Wang ${ }^{\mathrm{b}, \mathrm{c}}$ Xiaofang Suid Xiangyu Meng ${ }^{\mathrm{b}, \mathrm{c}}$ Tao Shen ${ }^{\mathrm{b}}$ \\ Xiuqing Huang ${ }^{b}$ Jun Guo ${ }^{b}$ Weiwei Fang ${ }^{b}$ Yong Man ${ }^{b}$ Jianzhong Xia Jian Li $^{b}$ \\ aDepartment of Biomedical Engineering, College of Engineering, Peking University, Beijing, 'Key \\ Laboratory of Geriatrics, Beijing Institute of Geriatrics \& Beijing Hospital, Ministry of Health, Beijing, \\ 'Peking University Fifth School of Clinical Medicine, Beijing, dFirst Affiliated Hospital of Jiamusi \\ University, Jiamusi, China
}

\section{Key Words}

MiR-301a • IL-6 PTEN • AKT • GSK glycogensis

\begin{abstract}
Background/Aims: IL-6 has been implicated in the pathogenesis of insulin resistance. MiR301 a plays an important role in various biological and pathological processes, including cellular development and differentiation, inflammation, apoptosis and cancer. However, whether miR-301a mediates IL-6-induced insulin resistance in hepatocytes remains unknown. Methods: The activation of AKT/GSK pathway and the level of glycogenesis were examed in NCTC 1469 cells transfected miR-301a mimics and inhibitor. Using computational miRNA target prediction database, PTEN was a target of miR-301a. The effect of miR-301a on PTEN expression was evaluated using Luciferase assay and western blot. A PTEN-specific siRNA was used to further determine the effect of PTEN on IL-6-induced insulin resistance. Results: In vivo and in vitro treatment with IL-6 was led to down-regulation of miR-301a, accompanied by impairment of theAKT/GSK pathway and glycogenesis. Importantly, over-expression of miR-301a rescued IL-6-induced decreased activation of the AKT/GSK pathway and hepatic glycogenesis. In contrast, down-regulation of miR-301a induced impaired phosphorylation of AKT and GSK, accompanied by reduced glycogenesis in hepatocytes. Moreover, our results indicate that suppression of PTEN, a target of miR-301a, diminished the effect of IL-6 on the AKT/GSK pathway and hepatic glycogenesis. Conclusion: We present novel evidence of the contribution of miR-301a to IL-6-induced insulin resistance by direct regulation of PTEN expression.

L. Dou and S.Wang contributed equally to this work.

Jianzhong $\mathrm{Xi}$

and Jian Li
Key Laboratory of Geriatrics, Beijing Hospital and Beijing Institute of Geriatrics, Ministry of Health, Beijing 100730 (China)

E-Mail lijian@bjhmoh.cn (JL); E-Mail jzxi@pku.edu.cn (JX) 


\section{Introduction}

Hepatic insulin resistance, defined as a decrease in the ability of hepatocytes to respond to insulin, is an important underlying cause of the metabolic syndrome that manifests itself in diseases such as type 2 diabetes, atherosclerosis or non-alcoholic fatty liver disease (NAFLD) [1]. Insulin is the principal regulator of whole body glucose homeostasis, which prevents the liver from producing excessglucose by regulating glycogenesis and gluconeogenesis. Therefore, decreased hepatic glycogen synthesis and failure to suppress glucose production are the hallmarks of insulin resistance in hepatocytes [2].

IL-6, an inflammatory cytokine, is secreted by and acts on a wide variety of tissues and cells [3]. Insulin resistance has been linked to increased circulating levels of IL-6, leading to chronic low-grade inflammation [4]. It has been demonstrated that chronically elevated IL-6 mediates the inhibitory effects on the PI3K/AKT pathway and on glucose metabolism $[5,6]$. Moreover, systemic depletion of IL-6 improved hepatic insulin action in a mouse model of obesity [7].

MicroRNAs are a class of short, single-stranded non-coding gene products that can post-transcriptionally regulate the expression of target genes through direct binding to the 3'-UTR of target mRNAs [8]. MicroRNAs are involved in many essential biological processes, including development, insulin secretion, and adipocyte differentiation. Moreover, it has been reported that pathogenesis of type 2 diabetes is associated with aberrant expression of miRNAs [9]. For example, miR-375, miR-9 and miR-124a have the potential to affect insulin secretion [10-12]. MiR-143, miR-27b, miR-130 and miR-519d may regulate adipocyte differentiation [13-15], and the miR-103, miR-107 [16], miR-29 [17] and miR-320 [18] families have been shown to regulate insulin sensitivity. Our previous study showed that over-expression of miR-200s can contribute to IL-6-induced hepatic insulin resistance [19].

It was reported that miR-301a may play an important role in various biological and pathological processes, including cellular development and differentiation, inflammation, apoptosis and cancer [20-22]. MiR-301a was shown to be up-regulated in pancreatic cancer and to activate NF-kB by negatively regulating the expression of the NF-kB-repressing factor (NKRF) gene [23]. Panguluri et al. reported that miR-301a was down-regulated in diabetic heart and modulated Kv4.2 by directly binding on its 3'-UTR, indicating the distinct association of mir-301a with diabetes [24].However, the role of miR-301a in hepatic insulin resistance and its underlying mechanisms remain unclear. In the present study, we found novel evidence suggesting that miR-301a contributes to IL-6-induced hepatic insulin resistance by regulating PTEN, one of its target genes.

\section{Materials and Methods}

Animals

Eighteen-week-old db/db mice (C57BL/Ks]) were obtained from the Peking University Health Science Center (originally purchased from Jackson Laboratory). Briefly, db/db mice $(n=5)$ and age-matched wildtype (WT) mice $(n=5)$ were fed a standard laboratory diet for 18 weeks.

Twelve-week-old male C57BL/6J mice were obtained from the Peking University Health Science Center. The mice $(n=10)$ were separated into two groups and fed a standard laboratory diet in a temperaturecontrolled $\left(20-24^{\circ} \mathrm{C}\right)$ and humidity-controlled (45-55\%) environment. A $12 \mathrm{~h} / 12 \mathrm{~h}$ light/dark cycle was maintained. For all experiments examining chronic IL-6 exposure, Alzet osmotic pumps (Durect, Cupertino, CA) with a 7-day pumping capacity and infusion rate of $1 \mu \mathrm{l} / \mathrm{h}$ were used. Pumps were filled to capacity with $16 \mu \mathrm{g} / \mathrm{ml}$ hIL-6 diluted in a vehicle $(0.9 \% \mathrm{NaCl}$ and $0.1 \% \mathrm{BSA})$ [6]. Following induction of halothane general anesthesia, pumps were implanted into the intrascapular subcutaneous space. Incisions were closed with interrupted absorbable sutures.

All animal procedures were performed in accordance with the National institutes of Health Animal Care and Use Guidelines. All animal protocols were approved by the Animal Ethics Committee at the Beijing Institute of Geriatrics. 


\section{Cellular Physiology Cell Physiol Biochem 2015;35:1413-1424 \begin{tabular}{l|l} 
DOI: 10.1159/000373962 & $\begin{array}{l}\text { O 2015 S. Karger AG, Basel } \\
\text { www.karger.com/cpb }\end{array}$ \\
\hline
\end{tabular} \\ Dou et al.: MiR-301a Activates Insulin Signal Pathway and Glycogenesis}

\section{Microarray analysis for miRNAs}

Microarray analysis was performed by Kangcheng Bio-tech Inc (Shanghai, China). To profile the expression of miRNAs in the two groups of mice, the miRNAs in the liver samples from $5 \mathrm{db} / \mathrm{db}$ mice and 5 control mice were analyzed by the miRCURY ${ }^{\mathrm{TM}}$ LNA Array (v.14.0 Exiqon). Total RNA was isolated using TRIzol (Invitrogen) and an RNeasyminikit (Qiagen) according to the manufacturers' instructions. The samples were labeled using the miRCURY ${ }^{\mathrm{TM}} \mathrm{Hy}^{\mathrm{TM}} / \mathrm{Hy}^{\mathrm{TM}}$ Power labeling kit and hybridized on miRCURY ${ }^{\mathrm{TM}}$ LNA Array (v.14.0 Exiqon) equipment. Scanning was performed with an Axon GenePix 4000B microarray scanner (Molecular Devices, Downingtown, PA, USA). GenePix pro V6.0 (Molecular Devices) was used to read the raw intensity of the image. The intensity of the green signal was calculated after the subtraction of background, as well as averaging of four replicated spots of each probe on the same slide. Median normalization method was used to obtain "Normalized Data": Normalized Data= (Foreground-Background) / Median, where the median was the $50 \%$ quartile of miRNA intensity, which was larger than 50 in all samples after correction for background [25].

\section{Cell culture}

NCTC 1469 cells derived from mouse liver cells (American Type Culture Collection) were cultured in low glucose Dulbecco's modified Eagle's medium (Invitrogen) supplemented with 20\% horse serum (Hyclone), $100 \mu \mathrm{nits} / \mathrm{ml}$ penicillin (Invitrogen), and $0.1 \mathrm{mg} / \mathrm{ml}$ streptomycin (Invitrogen) at $37^{\circ} \mathrm{C}$ in a humidified atmosphere of $95 \% \mathrm{O}_{2}$ and $5 \% \mathrm{CO}_{2}$.

\section{Transfection of miR-301a mimics and inhibitor}

The mimics and the inhibitor of miR-301a were purchased from Genepharm (Shanghai, China). The miRNA mimic control and inhibitor control were used as negative controls. Hiperfect transfection reagent (Qiagen) was used for the transfection of miR-301a mimics and inhibitors. The expression of miR-301a was detected by real-time PCR $48 \mathrm{~h}$ after transfection.

\section{Luciferase target assay}

For the luciferase assay, the 3'-untranslated region (UTR) of PTEN, including the binding sites for miR301a, was amplified from NCTC 1469 cells using the following primers (restriction sites are underlined):

PTEN-UTR-F-Sac I: TCGAGCTCGCAGAGGGCCAGGTCATGAAT

PTEN-UTR-R-Xba l: GCTCTAGAGCGAAGAGGCTGAATCGGGGTA

PCR was performed with genomic DNA isolated from NCTC 1469 cells, and the PCR product was subsequently digested with Sac I and Xba I (NEB). Then, the fragment was inserted into the pmirGLO (Promega) luciferase reporter vector. The procedures of PCR are described as follows: a hot start step at $95^{\circ} \mathrm{C}$ for $10 \mathrm{~min}$, followed by 40 cycles at $95^{\circ} \mathrm{C}$ for $15 \mathrm{~s}$ and $55^{\circ} \mathrm{C}$ for $45 \mathrm{~s}, 72^{\circ} \mathrm{C}$ for $30 \mathrm{~s}$.

To conduct the luciferase reporter assay, cells were seeded in 96-well plates at 5000 cells per well in $100 \mu \mathrm{l}$ medium. After incubation overnight, the cells were transfected with the modified firefly luciferase vector and miR-301a mimics with Effecten Reagent (Qiagen) according to the manufacturer's instructions. Forty-eight hours after transfection, the firefly and renilla luciferase activities were measured using the Dual-luciferase reporter assay system (Promega). To control the transfection efficiency, firefly luciferase activity was normalized to renillaluciferase activity.

\section{RNA isolation and real-time PCR}

Total RNA was harvested using TRIzol (Invitrogen). Enriched miRNA was isolated using miRNA isolation kit (TakaRa). A stem-loop reverse transcription-polymerase chain reaction (RT-PCR) was also executed on samples to detect and quantify mature miRNAs by using stem-loop antisense primer mix and avian myeloblastosis virus transcriptase (TaKaRa).

The cDNA preparations were tested by real-time PCR based on the SYBR Green I method, according to the manufacturer's instructions (TaKaRa). The amplification and detection of specific products were performed according to the manufacturer's protocol with the iQ5 system (BioRad). U6 small nucleolar RNA was used as the housekeeping small RNA reference gene. The relative gene expression was normalized to U6 small nucleolar RNA. Each reaction was performed in triplicate, and analysis was performed by the $2^{-\triangle \Delta C T}$ method. Nucleotide primers used for reverse transcription were as follows (5'-3'): miR-301a, GTCGTATCCAGTGCAGGGTCCGAGGTATTCGCACTGGATACGACGCTTTG; U6, GTCGTATCCAGTGCAGGGTCCGAG 
GTATTCGCACTGGATACGACAAAA-ATATG. The nucleotide primers used for real-time PCR were as follows (5'-3'): miR-301a forward, GCGAGCAGTGCAATAGTATTGT; U6 forward, GCGCGTCGTGAAGCGTTC; universal reverse primer, GTGCAGG GTCCGAGGT.

\section{Western blot analysis}

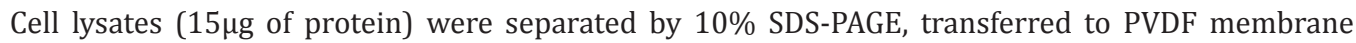
(Millipore), blocked with $8 \%$ nonfat dry milk, and probed with the antibodies at $4^{\circ} \mathrm{C}$ overnight. The blots were incubated with HRP-conjugated anti-IgG, followed by detection with ECL (Millipore). The antibodies against AKT, phosphorylation of AKT ( $\mathrm{Ser}^{473}$ ), PTEN, glycogen synthase kinase (GSK), and phosphorylation of GSK $\left(\operatorname{Ser}^{9}\right)$ were purchased from Cell Signaling.

\section{Measurement of glycogen content}

The glycogen levels were measured in the cells or in liver tissues incubated for $3 \mathrm{~h}$ in the presence of 1 $\mathrm{nmol} / \mathrm{L}$ insulin (Usbio) using a glycogen assay kit (Biovision).

\section{Statistical analysis}

All values are represented as the mean \pm S.E.M. of the indicated number of measurements. The nonparametric Mann-Whitney test was used to determine statistical differences between two mice groups. A one-way analysis of variance test for post-hoc multiple comparisonwas used to determine significance, with a value of $\mathrm{p}<0.05$ indicating statistical significance.

\section{Results}

MiR-301a is down-regulated in the livers of $\mathrm{db} / \mathrm{db}$ mice

To examine the changes of the microRNA expression in cases of hepatic insulin resistance, the miRNAs in the livers of $d b / d b$ mice $(n=5)$ and control mice $(n=5)$ were analyzed by miRNA microarray. The results of the miRNA microarray and real-time PCR showed that miR-301a expression was reduced in the livers of $\mathrm{db} / \mathrm{db}$ mice (Table 1 , Fig. 1A). As shown in Fig. 1B, phosphorylation of AKT and GSK was decreased in the livers of db/ $\mathrm{db}$ mice, indicating that activation of the AKT/GSK pathway was impaired. Moreover, the glycogen levels in the livers of $\mathrm{db} / \mathrm{db}$ mice were significantly decreased, demonstrative of a state of insulin resistance (Fig. 1C). Notably, the serum level of IL-6 was increased in the $\mathrm{db} / \mathrm{db}$ mice (Fig. 1D).These in vivo observations suggest that down-regulated miR-301a is probably associated with hepatic insulin resistance.

\section{IL-6 treatment leads to decreased expression of miR-301a in NCTC 1469 cells}

There are many factors that could induce insulin resistance, such as high glucose, free fatty acids (FFA) and inflammatory factors. Our previous study indicated that the levels of serum glucose and FFA were increased in $\mathrm{db} / \mathrm{db}$ mice [19]. Therefore, an in vitro assessment of the

Table 1. The results of microRNA microarray analysis. D: db/dbmouse C: wild type mouse

\begin{tabular}{|c|c|c|c|c|c|c|c|}
\hline \multirow[t]{2}{*}{ Name } & \multirow{2}{*}{$\begin{array}{l}\text { Change } \\
(\mathrm{D} / \mathrm{C})\end{array}$} & \multicolumn{2}{|c|}{ Foreground } & \multicolumn{2}{|c|}{$\begin{array}{l}\text { Foreground- } \\
\text { background }\end{array}$} & \multicolumn{2}{|c|}{ Normalized } \\
\hline & & $\mathrm{C}$ & $\mathrm{D}$ & $\mathrm{C}$ & $\mathrm{D}$ & $\mathrm{C}$ & $\mathrm{D}$ \\
\hline $\mathrm{miR}-301 \mathrm{a}$ & 0.556 & 120 & 92 & 54.5 & 19.5 & 0.214 & 0.076 \\
\hline $\operatorname{miR}-19 \mathrm{a}$ & 0.621 & 362 & 258 & 288.5 & 180.5 & 1.131 & 0.703 \\
\hline $\mathrm{miR}-200 \mathrm{a}$ & 0.105 & 168.5 & 77 & 104 & 11 & 0.408 & 0.043 \\
\hline $\mathrm{miR}-200 \mathrm{~b}$ & 0.476 & 298 & 179.5 & 228.5 & 109.5 & 0.896 & 0.427 \\
\hline miR-291b-3p & 1.88 & 131 & 192.5 & 61.5 & 116.5 & 0.241 & 0.454 \\
\hline
\end{tabular}


A

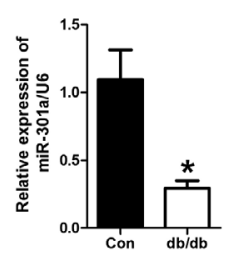

C

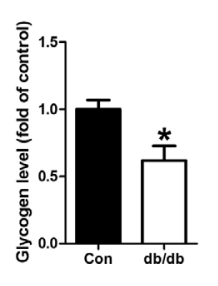

B
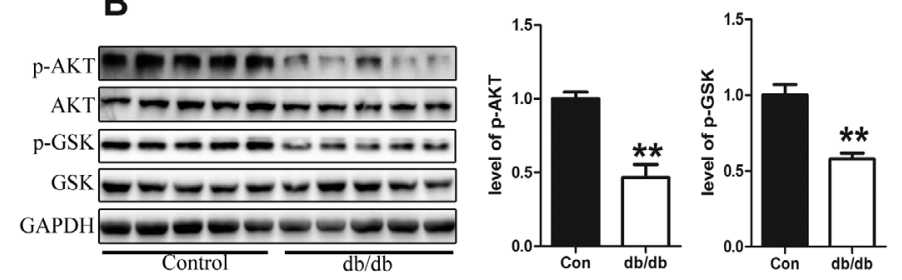

D

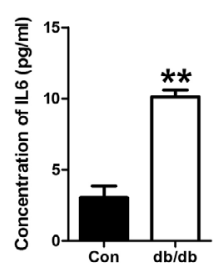

Fig. 1. MiR-301a is down-regulated in the livers of $\mathrm{db} / \mathrm{db}$ mice. The $\mathrm{db} / \mathrm{db}$ mice were fed with a standard diet for 12 weeks. miR-301aexpression was analyzed by real-time PCR (A). The activation of AKT/GSK pathway (B), glycogen content (C) and the level of IL-6 in serum (D) were measured. Data represent the mean \pm S.E.M., $\mathrm{N}=5 .{ }^{*} \mathrm{p}<0.05 ;{ }^{* *} \mathrm{p}<0.01$ by ANOVA (vs. control).

Fig. 2. IL-6 treatment leads to decreased expression of miR301a in NCTC 1469 cells. The level of miR-301a was analyzed in mouse NCTC 1469 hepatocytes treated with $33.3 \mathrm{mmol} / \mathrm{L}$ glucose for $48 \mathrm{~h}(\mathrm{~A}), 10 \mathrm{ng} /$ $\mathrm{ml}$ TNF- $\alpha$ for $24 \mathrm{~h}$ (B), or 10 $\mathrm{ng} / \mathrm{ml} \mathrm{IL-6}$ for $24 \mathrm{~h}(\mathrm{C})$, and in the livers of 12-week-old male C57BL/6J mice injected with $16 \mu \mathrm{g} / \mathrm{ml}$ IL- 6 by pumps for 7 days(D). Data represent the mean \pm S.E.M., $\mathrm{N}=4$ independent experiments or $\mathrm{N}=5$ mice. * $\mathrm{p}<0.05$; ** $\mathrm{p}<0.01$ by ANOVA test (vs. control).

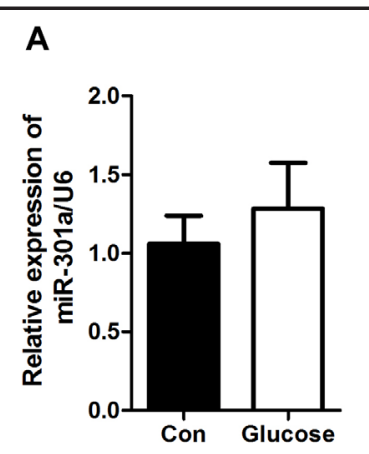

C

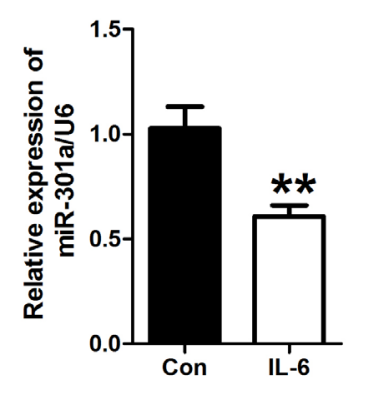

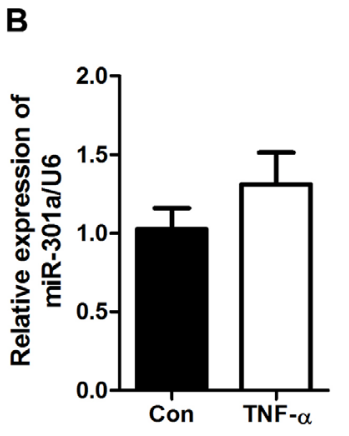

D

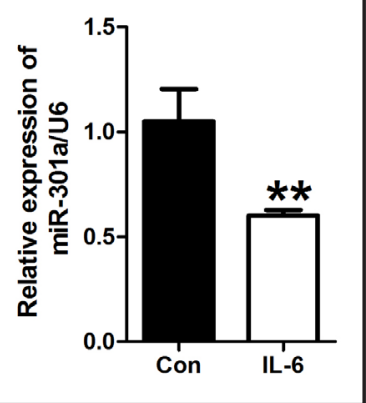

potential involvement of miR-301a in IL-6-induced hepatic insulin resistance is necessary. Mouse NCTC 1469 hepatocytes were treated with $33.3 \mathrm{mmol} / \mathrm{L}$ glucose for $48 \mathrm{~h}, 10 \mathrm{ng} / \mathrm{ml}$ hIL- 6 for $24 \mathrm{~h}$ or $10 \mathrm{ng} / \mathrm{ml}$ TNF- $\alpha$ for $24 \mathrm{~h}$ to induce insulin resistance, as described previously [26]. The expression of miR-301a was down-regulated by IL- 6 treatment, but not by glucose or TNF- $\alpha$ treatment (Figs.2A, Band C). To confirm the effect of IL-6 on the expression of miR- 
Fig. 3. Over-expression of miR301a rescues IL-6-induced decreased activation of the AKT/ GSK pathway and hepatic glycogenesis. The glycogen content and activation of the AKT/GSK pathway were measured in the NCTC 1469 cells treated with 10 $\mathrm{ng} / \mathrm{ml} \mathrm{IL-6} \mathrm{for} 24$ $\mathrm{h}$ (A) and in the livers of mice injected with IL-6 for 7 days (B). The miR-301a level was detected in the NCTC 1469 cells transfected with miR-301a mimics (C) and an miR-301a inhibitor (D). The phosphorylation of AKT and GSK were analyzed in the NCTC 1469 cells transfected with miR-301a mimics (E) and
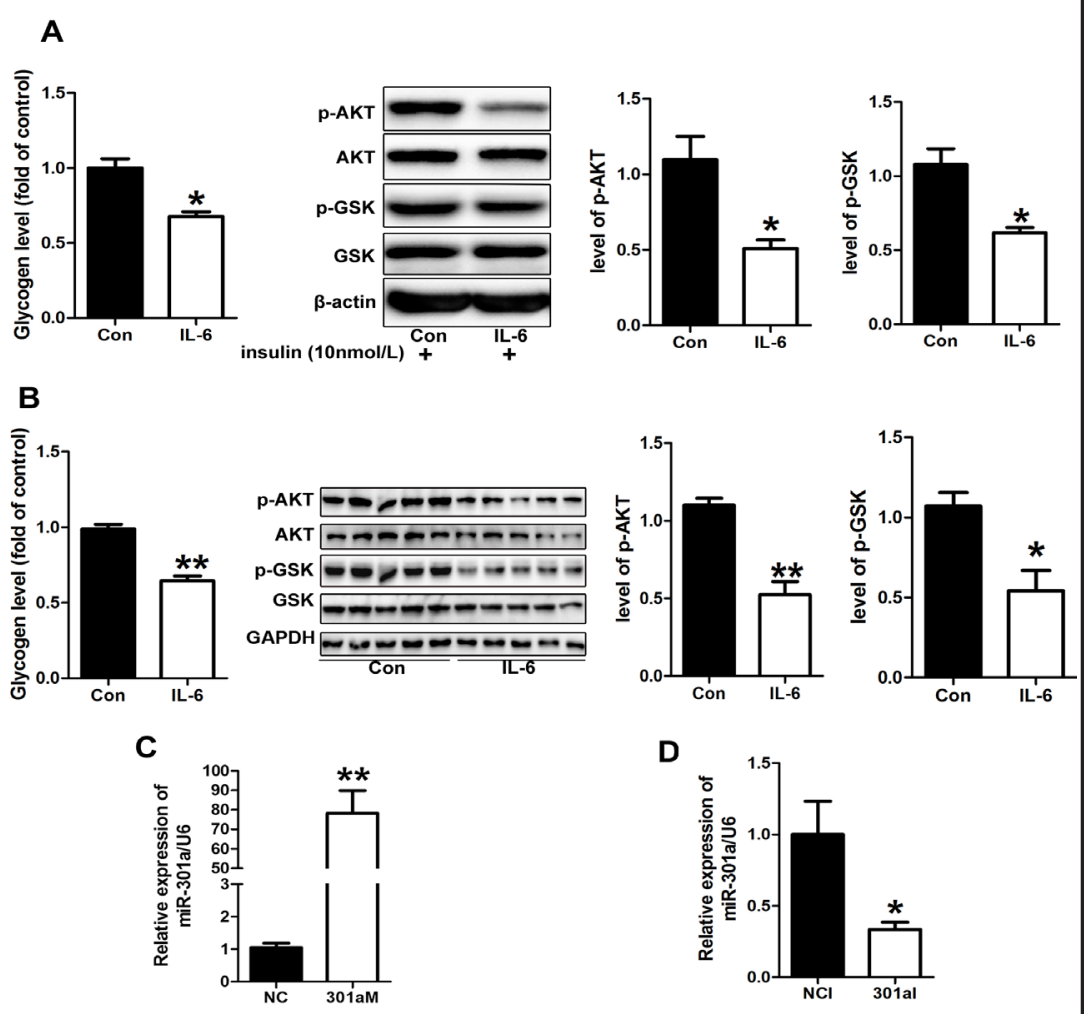

D
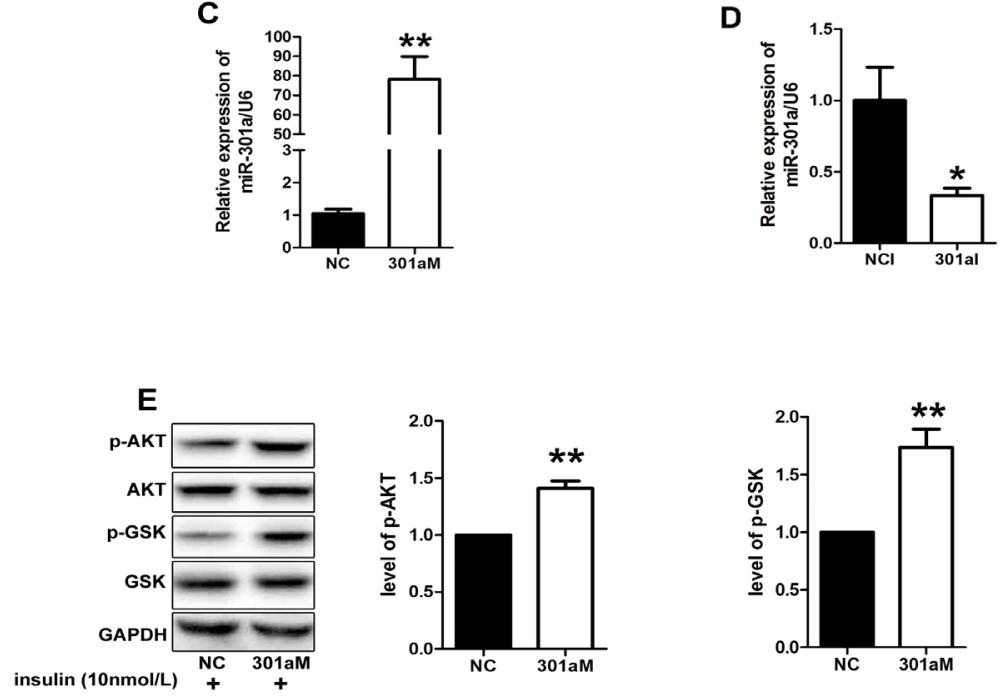

continued

an miR-301a inhibitor (F). The activation of the AKT/GSK pathway and content of glycogen were measured in the NCTC 1469 cells treated with $10 \mathrm{ng} / \mathrm{ml} \mathrm{IL-6}$ after transfection with miR-301a mimics (G) and miR301 a inhibitor $(H)$. Data represent the mean \pm S.E.M., $N=4$ independent experiments or $N=5$ mice. ${ }^{*} p<0.05$; ** $\mathrm{p}<0.01$ by ANOVA(vs. control or IL-6).

301a in vivo, 12-week-old male C57BL/6J mice were injected with $16 \mu \mathrm{g} / \mathrm{ml}$ IL-6 by pumps for 7 days, and the livers of the mice were collected. As shown in Fig. 2D, the expression of miR-301a was significantly decreased in the livers of mice injected with IL-6. These results suggest that IL- 6 could down-regulate the expression of miR-301a both in vitro and in vivo.

Over-expression of miR-301a rescues IL-6-induced decreased activation of AKT/GSK pathway and hepatic glycogenesis

Next, we investigated the effect of IL- 6 on glycogenesis. NCTC 1469 cells were treated with $10 \mathrm{ng} / \mathrm{ml} \mathrm{IL-6}$ for $24 \mathrm{~h}$. As shown in Fig. 3A, the IL-6 treatment significantly decreased glycogen levels and phosphorylation of AKT and GSK in NCTC 1469 cells. Similarly, the levels of glycogen were significantly reduced, accompanied by impairment of the AKT/GSK pathway in the livers of mice injected with IL-6 (Fig. 3B). 


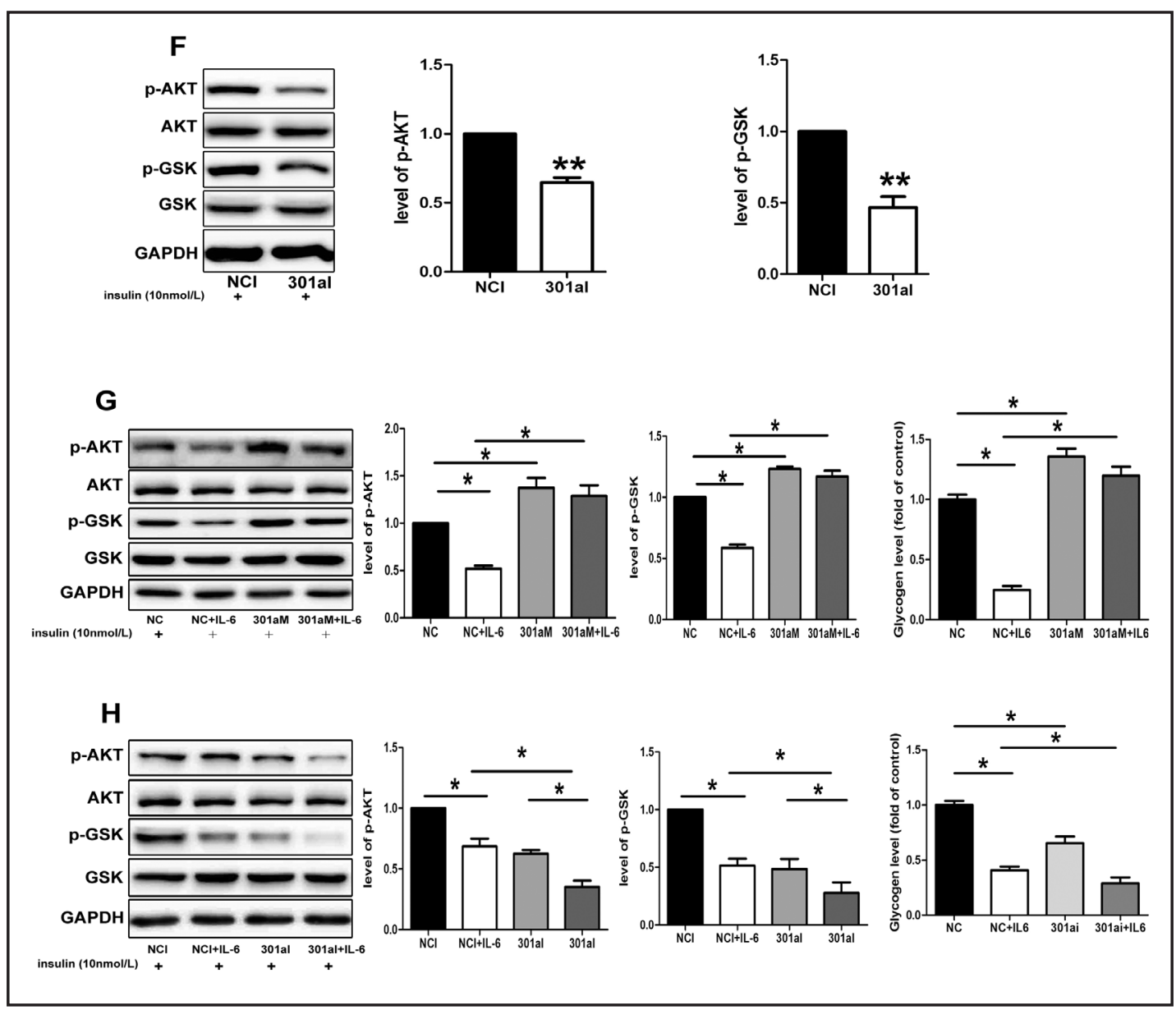

To determine the effect of miR-301a on AKT/GSK pathway activation and glycogenesis in hepatocytes, we transfected miR-301a mimics and inhibitors into NCTC1469 cells for $48 \mathrm{~h}$. The results of real-time PCR showed that the level of miR-301a was increased up to 70- to 80-fold in the NCTC 1469 cells transfected with miR-301a mimics compared to those transfected with a negative miRNA mimic control, whereas the level of miR-301a decreased $30-40 \%$ in the NCTC 1469 cells transfected with an miR-301a inhibitor compared with those transfected with the negative miRNA inhibitor control (Fig. 3C, D). Moreover, miR-301a mimics improved phosphorylation of AKT and GSK in NCTC 1469 cells (Fig. 3E), while the miR-301a inhibitor blocked activation of the AKT/GSK pathway (Fig. 3F).

Finally, To further assess the role of miR-301a in IL-6-induced hepatic insulin resistance, NCTC 1469 cells were treated with $10 \mathrm{ng} / \mathrm{ml}$ IL-6 for $24 \mathrm{~h}$ followed by transfection with miR-301a mimics or inhibitors for $48 \mathrm{~h}$. Up-regulation of miR-301a rescued IL-6-induced suppression of the AKT/GSK pathway and glycogenesis in the NCTC 1469 cells (Fig. 3G). In contrast, down-regulation of miR-301a further promoted IL-6-induced impairment of theAKT/GSK pathway activation and glycogenesis in NCTC 1469 cells (Fig. 3H). Taken together, these results suggest that miR-301a can modulate the activation of the AKT/GSK pathway and glycogenesis in hepatocytes.

MiR-301 a regulates the expression of PTEN by directly binding to its 3'-UTR

Analysis for the target genes of miR-301a by Miranda, TargetScan and PicTar predicted PTEN as a target of miR-301a. There are several binding sites for the miR-301a at nts 22003300 of the PTEN 3'-UTR (Fig. 4A). Therefore, we cloned PTEN 3'-UTR and inserted it into a pmiRGLO vector. A luciferase reporter assay was used to assess if miR-301a directly binds to the 3'-UTR of PTEN. As shown in Fig. 4B, over-expression of miR-301a could dramatically 
Fig. 4. MiR-301a regulates the expression of PTEN by directly binding to its 3'-UTR.The sequences of miR-301a binding sites of the PTEN gene were analyzed by TargetScan (A). The luciferase activity was significantly reduced in the NCTC1469 cells co-transfected with a luciferase reporter vector containing the PTEN-3'-UTR and miR-301a mimics. The miR-301a inhibitor slightly increased the luciferase activity (B). The levels of PTEN in the NCTC 1469 cells transfected with miR301a mimics (C) and miR-301a inhibitor (D) were measured by western blot. Data represent the mean \pm S.E.M., $\mathrm{N}=4$ independent experiments. ${ }^{* *} \mathrm{p}<0.01$; ${ }^{* * *}$ $\mathrm{p}<0.001$ by ANOVA (vs. control).

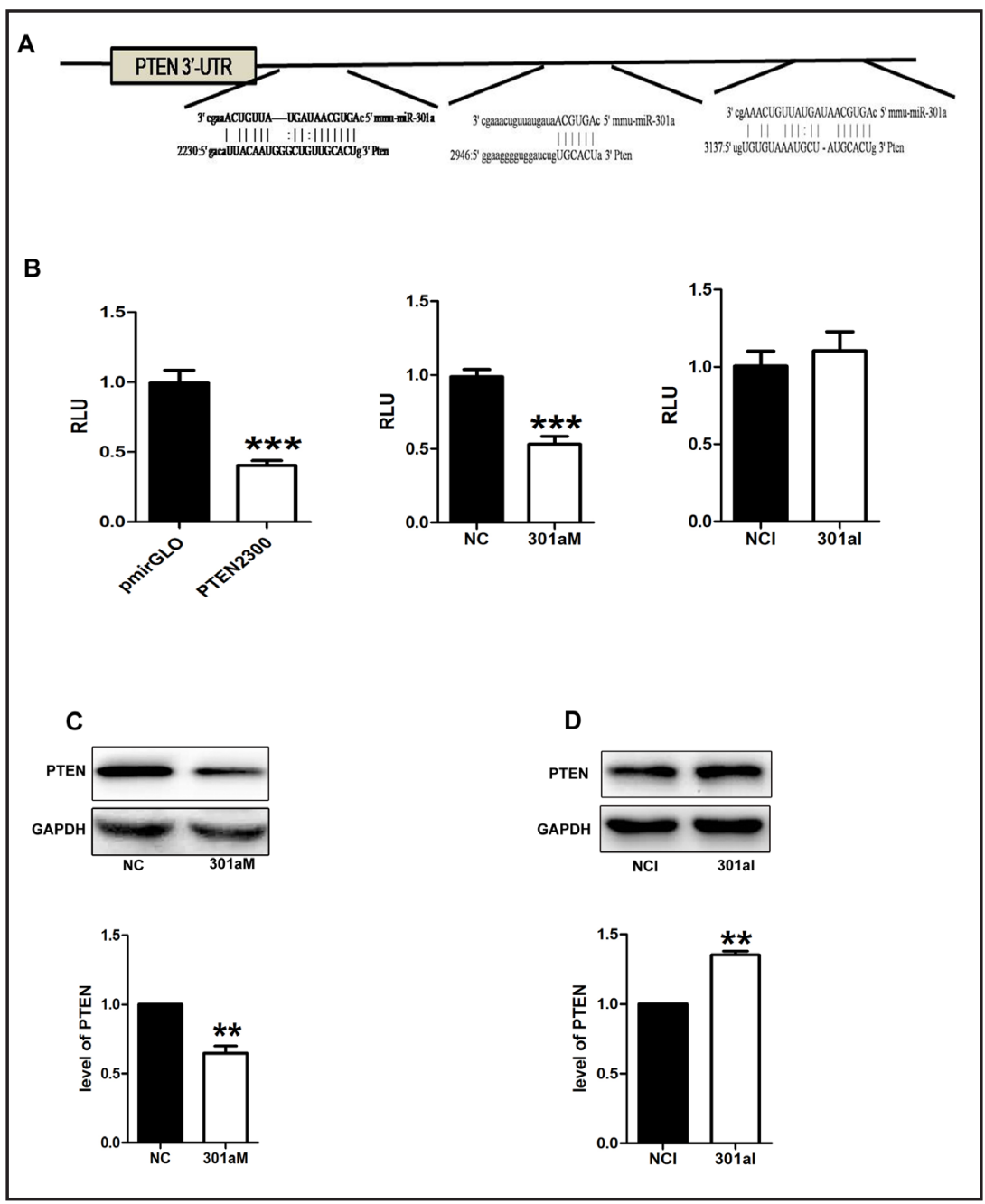

reduce the luciferase activity in the NCTC1469 cells transfected with the luciferase reporter vector containing the 3'-UTR of PTEN. Moreover, PTEN was down-regulated in the NCTC1469 cells transfected with miR-301a mimics (Fig. 4C). In contrast, miR-301a inhibitor led to the up-regulation of PTEN (Fig. 4D). Our data demonstrate that miR-301a could regulate PTEN expression by directly binding to its 3'-UTR.

\section{PTEN participates in IL-6-induced hepatic insulin resistance}

As shown in Fig. 5A, expression of PTEN was significantly regulated in the livers of $\mathrm{db} /$ $\mathrm{db}$ mice. The level of PTEN was also increased in the NCTC 1469 cells treated with IL-6 (Fig. 5B). Moreover, the level of PTEN was elevated in the livers of mice injected with IL-6 (Fig. 5C). To further determine the role of PTEN in IL-6-induced hepatic insulin resistance, siRNA(si-1381) targeting PTEN mRNA was transfected into NCTC 1469 cells. Both protein levels and mRNA levels of PTEN were decreased 70-60\% compared with those transfected with the negative siRNA control (Fig. 5D). Down-regulation of PTEN rescued the effects of IL- 6 on the activation of the AKT/GSK pathway and glycogenesis in NCTC 1469 cells (Fig. 5E). To determine whether the inhibitory effect of PTEN affects the PI3K pathway, the PI3K inhibitor LY294002 was used to block the PI3K pathway in the NCTC1469 cells transfected with siRNA-PTEN. Fig. 5F shows that PTEN did not affect glycogenesis after treatment with $10 \mathrm{nmol} / \mathrm{L} \mathrm{LY294002}$ for $24 \mathrm{~h}$, suggesting that PTEN, a target of miR-301a, participates in IL-6-induced hepatic insulin resistance. 


\section{Cellular Physiology Cell Physiol Biochem 2015;35:1413-1424}

and Biochemistry

Fig. 5. PTEN participates in IL-6-induced hepatic insulin resistance. The levels of PTEN were measured in the livers of $\mathrm{db} / \mathrm{db}$ mice (A), the NCTC 1469 cells treated with $10 \mathrm{ng} / \mathrm{ml}$ IL-6 for $24 \mathrm{~h}$ (B), and the livers of mice injected with IL-6 for 7 days (C). The levels of PTEN protein and mRNA were analyzed in the NCTC 1469 cells transfected with siRNA (si-1381) targeting PTEN mRNA for $48 \mathrm{~h}$ (D). The activation of AKT/GSK pathway and glycogenesis were analyzed in the NCTC 1469 cells transfected with si-1381 for $48 \mathrm{~h}$ followed by $10 \mathrm{ng} / \mathrm{ml} \mathrm{IL-} 6$ treatment for $24 \mathrm{~h}(\mathrm{E})$. The levels of glycogen were measured in the NCTC 1469 cells transfected with si-1381PTEN for $48 \mathrm{~h}$ followed by treatment with $30 \mu \mathrm{g} /$ ml LY294002 for $24 \mathrm{~h}$ (F). Data represent the mean \pm S.E.M., $N=4$ independent experiments or $\mathrm{N}=5$ mice. ${ }^{*} \mathrm{p}<0.05$; ${ }^{* *} \mathrm{p}<0.01$ by ANOVA (vs. control or IL-6 or si-1381).

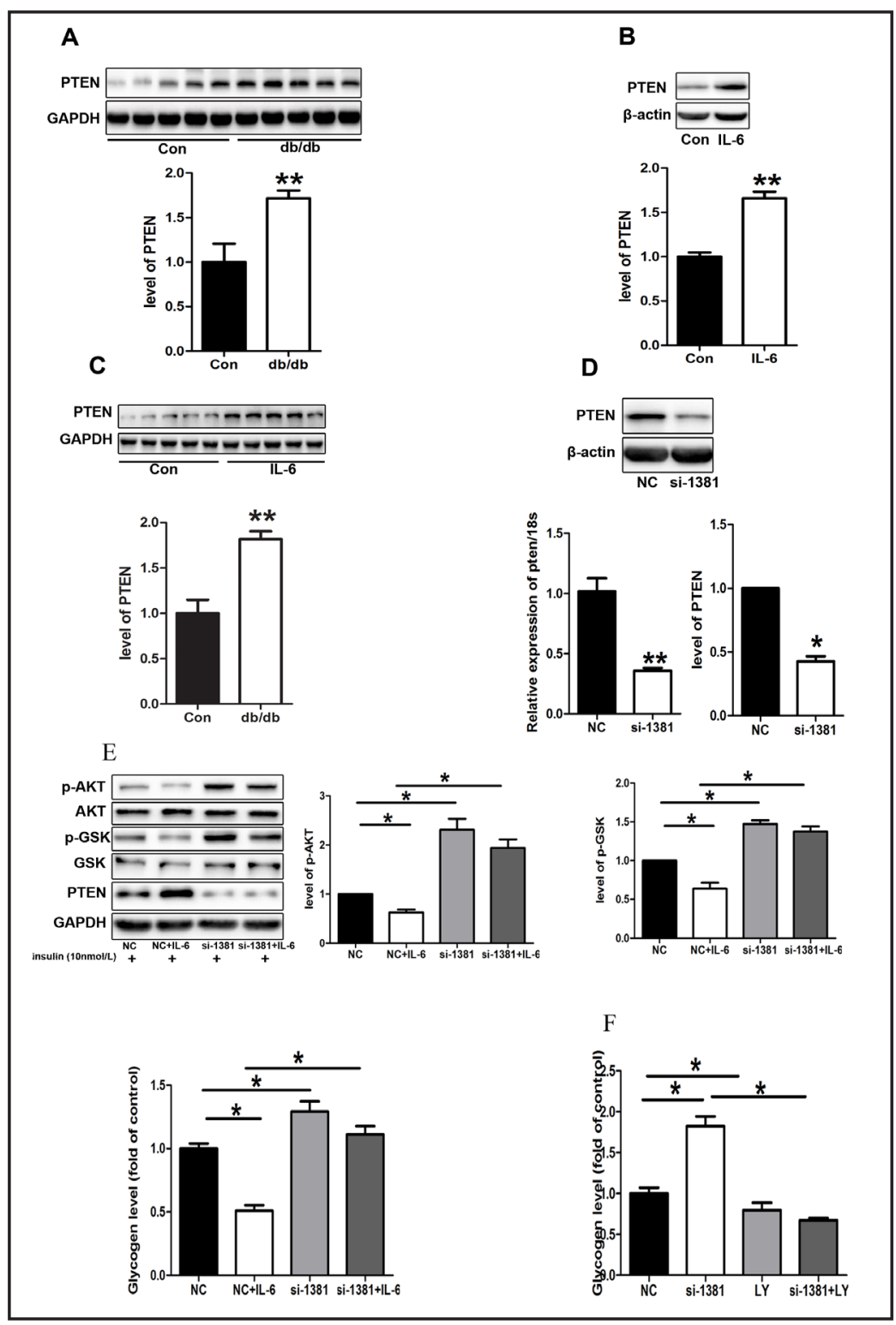

\section{Discussion}

In the present study, we found that (i) the expression of miR-301a was decreased in the livers of $\mathrm{db} / \mathrm{db}$ mice accompanied by increased serum IL- 6 and reduced glycogenesis; (ii) IL-6 treatment both in vivo and in vitro led to down-regulated miR-301a and impairment of the AKT/GSK pathway and of glycogenesis; (iii) over-expression of miR-301a rescued IL-6-induced decreased activation of the AKT/GSK pathway and hepatic glycogenesis; and (iv) suppression of PTEN, a target of miR-301a, diminished the effect of IL-6 on the AKT/ GSK pathway and hepatic glycogenesis. In conclusion, we present novel evidence suggesting that miR-301a contributes to IL-6-induced insulin resistance by directly regulating PTEN expression.

Insulin resistance is the principle step towards the progression of type 2 diabetes. It has been reported that chronic low-grade inflammation contributed to the pathogenesis of insulin resistance in type 2 diabetes. Increased circulating levels of IL- 6 in chronic disease states plays a critical role in the regulation of insulin resistance in peripheral tissues and is used as a marker of insulin resistance [4]. In the liver, insulin activates the PI3K/AKT 
Fig. 6. The molecular mechanisms by which miR301 a contributes to IL-6-induced hepatic insulin resistance. IL-6 blocks the activity of AKT/GSK pathway and glycogenesis via down-regulation of miR-301a, accompanied by up-regulation of PTEN expression.

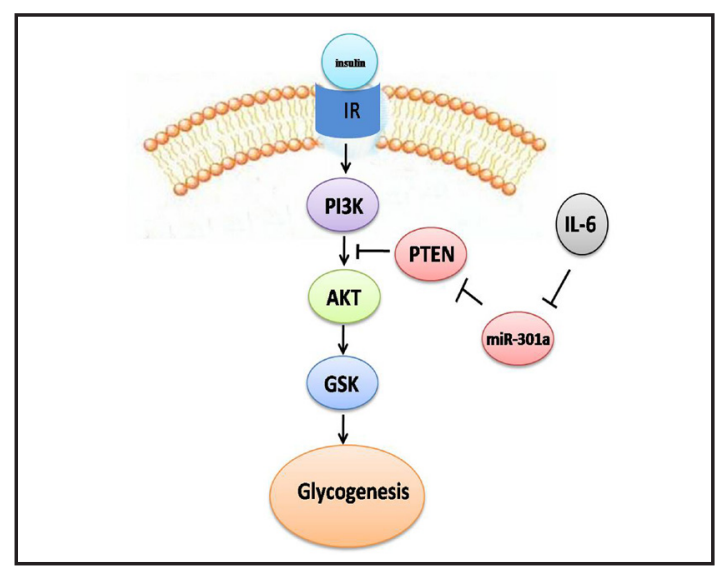

signaling cascade, leading to the phosphorylation and inactivation of GSK. Hence, glycogen synthase, the target of GSK, is freed of inhibitory phosphorylation, and glycogen synthesis is induced upon insulin stimulation. Our results show that phosphorylation of AKT and GSK were impaired in NCTC 1469 cells treated with $10 \mathrm{ng} / \mathrm{ml}$ IL-6 for $24 \mathrm{~h}$. Similarly, the levels of glycogen were significantly decreased, accompanied by impaired phosphorylation of AKT and GSK in the livers of mice injected with IL-6, suggesting that IL-6 induces hepatic insulin resistance by suppression of the AKT/GSK pathway.

In O'Neill's study, mice was implanted with subcutaneous osmotic mini-pumps containing IL-1B and IL- 6 at low picogram per milliliter concentration consistent with serum levels. Mixture of IL- 6 and IL-1B, not only IL-6, was used in their experiments. They found that low-grade inflammation could trigger $\beta$-cell decline early in the development of type 2 diabetes, and suggested that IL-1B and IL- 6 might have a synergistic effect on $\beta$-cell function [27]. In the present study, $16 \mu \mathrm{g} / \mathrm{ml} \mathrm{IL-6}$ was used in vivo, as previously described in Reference 6 in which mice chronically treated for 5 days with hIL-6 $(16 \mu \mathrm{g} / \mathrm{ml})$ with Azlet pumps. Chronic IL- 6 treatment with this dose of IL- 6 in vivo could selectively impair hepatic insulin signaling in vivo.

It has been reported that obesity, hyperlipidemia and insulin resistance are strongly associated with aberrant expression of multiple essential miRNAs in the liver [9]. The contribution of miRNA to IL-6-induced hepatic insulin resistance remains in question. We analyzed microRNA profile in the $\mathrm{db} / \mathrm{db}$ mouse liver using miR quantification microarray. The results showed that 31 microRNAs were up-regulated, while 81 microRNAs were downregulated in the $\mathrm{db} / \mathrm{db}$ mouse liver. We have analyzed the role of some microRNAs such as miR-200s and miR-291 in hepatic insulin resistance $[19,28]$. The results of microarray also indicated that miR-301a was down-regulated significantly in the $\mathrm{db} / \mathrm{db}$ mouse liver. Analysis for the target genes of miR-301a by Miranda, TargetScan and PicTar predicted PTEN as a target of miR-301a. Moreover, our previous study suggested that down-regulation of PTEN increase the activity of PI3K-AKT pathway. Therefore, in the present study, we further investigated the contribution of miR-301a to IL-6-induced insulin resistance by direct regulation of PTEN expression. A previous study showed that up-regulated miR-301a in breast cancer promoted tumor metastasis by targeting PTEN and activating Wnt/ $\beta$-catenin signaling [22]. Panguluri et al. reported that miR-301a may be a central regulator for expression of Kv4.2. in cases of diabetes [24]. However, the role of miR-301a in the pathogenesis of hepatic insulin resistance has not been reported. Our results show that $\mathrm{db} / \mathrm{db}$ mice exhibited impaired the AKT/GSK pathway activation, reduced glycogen content and down-regulated miR-301a in the liver, accompanied by increased serum IL- 6 . To determine the contribution of IL- 6 toward the down-regulation of miR-301a, we extended these observations from $\mathrm{db} / \mathrm{db}$ mice to a mouse hepatocyte cell line, NCTC 1469.The results show that treatment with $10 \mathrm{ng} / \mathrm{ml}$ IL-6 for 24 $\mathrm{h}$ reduced the expression of miR-301a, whereas there was no change in expression of miR301a in the NCTC 1469 cells treated witheither $33.3 \mathrm{mmol} / \mathrm{L}$ glucose or $10 \mathrm{ng} / \mathrm{ml} \mathrm{TNF-} \alpha$ for $24 \mathrm{~h}$. Similarly, down-regulation of miR-301a by IL- 6 was assessed in the livers of C57BL/6 
mice injected with IL-6. Up-regulation of miR-301a by transfection of miR-301a mimics rescued IL-6-induced suppression of the AKT/GSK pathway and glycogenesis in NCTC 1469 cells.

Analysis for the target genes of miR-301a by Miranda, TargetScan and PicTar predicted PTENas the target of miR-301a, and there are several binding sites for miR-301a at the PTEN 3'-UTR.We found a negative correlation between miR-301a and PTEN in the livers ofdb/ $\mathrm{db}$ mice and C57BL/6J mice injected with IL-6 and in the NCTC1469 cells exposed to IL-6, consistent with the suppressive role of miR-301a in PTEN regulation. Our data suggest that miR-301a could inhibit the expression of PTEN by directly binding to its 3'-UTR. It has been demonstrated that PTEN is a negative regulator of PI3K/AKT signaling. Down-regulation of PTEN could ameliorate insulin resistance in peripheral tissues such as skeletal muscle and adipose [29].Therefore, we looked for a correlation between the expression of PTEN and miR-301a in hepatic insulin resistance. PTEN-targeting siRNA was transfected into NCTC 1469 cells. The results show that down-regulation of PTEN rescued IL-6-induced impaired activation of AKT and GSK and glycogenesis in NCTC1469 cells. Moreover, PTEN could not affect glycogenesis after treatment with the PI3K inhibitor LY294002. These results demonstrate that PTEN participates in IL-6-induced hepatic insulin resistance by regulating PI3K/AKT signaling. The results reveal that miR-301a acts as an important regulator of insulin signaling in hepatocytes, which may provide novel therapeutic target for treatment of hepatic insulin resistance. However, the effect of miR-301a on insulin signaling pathway in vivo need to be explored.

In conclusion, as shown in Fig. 6, miR-301a contributes to IL-6-induced hepatic insulin resistance. Our results suggest that IL-6 could suppress the activation of the AKT/GSK pathway and synthesis of glycogen via down-regulation of miR-301a, accompanied by upregulation of PTEN. These findings provide mechanistic insight into the effects of miR-301a on the regulation of the PI3K/AKT pathway and the synthesis of glycogen in hepatocytes.

\section{Acknowledgements}

This work was supported by grants from the National Basic Research Program of China (2012CB517502, 2014CB910503) and the National Natural Science Foundation of China (81070634, 81270887). The funders had no role in study design, data collection and analysis, decision to publish, or preparation of the manuscript.

\section{Disclosure Statement}

The authors have declared that no competing interests exist.

\section{References}

1 Petersen KF, Shulman GI: New insights into the pathogenesis of insulin resistance in humans using magnetic resonance spectroscopy. Obesity 2006;14:34-40.

2 Leclercq IA, Da Silva Morais A, Schroyen B, Van Hul N, Geerts A: Insulin resistance in hepatocytes and sinusoidal liver cells: mechanisms and consequences. J Hepatol 2007;47:142-156.

3 Kim JH, Bachmann RA, Chen J: Interleukin-6 and insulin resistance. Vitam Horm 2009;80:613-633.

4 Sarvas JL, Khaper N, Lees SJ: The IL-6 Paradox: Context Dependent Interplay of SOCS3 and AMPK. J Diabetes Metab 2013. Doi. 10.4172/2155-6156.S13-003.

5 Shi H, Cave B, Inouye K, Bjorbaek C, Flier JS: Overexpression of suppressor of cytokine signaling 3 in adipose tissue causes local but not systemic insulin resistance. Diabetes 2006;55:699-707.

6 Klover PJ, Zimmers TA, Koniaris LG, Mooney RA: Chronic exposure to interleukin-6 causes hepatic insulin resistance in mice. Diabetes 2003;52:2784-2789.

7 Klover PJ, Clementi AH, Mooney RA: Interleukin-6 depletion selectively improves hepatic insulin action in obesity. Endocrinology 2005;146:3417-27.

8 Bartel DP: MicroRNAs: genomics, biogenesis, mechanism, and function. Cell 2004;116:281-297. 
9 Williams MD, Mitchell GM: MicroRNAs in insulin resistance and obesity. Exp Diabetes Res 2012;2012:484696.

10 Poy MN, Eliasson L, Krutzfeldt J, Kuwajima S, Ma X, Macdonald PE, Pfeffer S, Tuschl T, Rajewsky N, Rorsman P, Stoffel M: A pancreatic islet-specific microRNA regulates insulin secretion. Nature 2004;432:226-230.

11 Plaisance V, Abderrahmani A, Perret-Menoud V, Jacquemin P, Lemaigre F, Regazzi R: MicroRNA-9 controls the expression of Granuphilin/Slp4 and the secretory response of insulin-producing cells. J Biol Chem 2006;28:26932-26942.

12 Baroukh N, Ravier MA, Loder MK, Hill EV, Bounacer A, Scharfmann R, Rutter GA, Van Obberghen E: MicroRNA-124a regulates Foxa2 expression and intracellular signaling in pancreatic beta-cell lines. J Biol Chem 2007;282:19575-19588.

13 Esau C, Kang X, Perala E, Hanson E, Marcusson EG, Ravichandran LV, Sun Y, Koo S, Perera RJ, Jain R, Dean NM, Freier SM, Bennett CF, Lollo B, Griffey R: MicroRNA-143 regulates adipocyte differentiation. J Biol Chem 2004;279:52361-52365.

14 Karbiener M, Fischer C, Nowitsch S, Opriessnig P, Papak C, Aihaud G, Dani C, Amri EZ, Scheideler M: microRNA miR-27b impairs human adipocyte differentiation and targets PPARgamma. Biochem Biophys Res Commun 2009;390:247-251.

15 Martinelli R, Nardelli C, Pilone V, Buonomo T, Liguori R, Castano I, Buono P, Masone S, Persico G, Forestieri P, Pastore L, Sacchetti L: miR-519d overexpression is associated with human obesity. Obesity 2010;18:2170-2176.

16 Trajkovski M, Hausser J, Soutschek J, Bhat B, Akin A, Zavolan M, Heim MH, Stoffel M: MicroRNAs 103 and 107 regulate insulin sensitivity. Nature 2011;474:649-653.

17 He A, Zhu L, Gupta N, Chang Y, Fang F: Overexpression of micro ribonucleic acid 29, highly up-regulated in diabetic rats, leads to insulin resistance in 3T3-L1 adipocytes. Mol Endocrinol 2007;21:2785-2794.

18 Ling HY, Ou HS, Feng SD, Zhang XY, Tuo QH, Chen LX, Zhu BY, Gao ZP, Tang CK, Yin WD, Zhang L, Liao DF: CHANGES IN microRNA (miR) profile and effects of miR-320 in insulin-resistant 3T3-L1 adipocytes. Clin Exp Pharmacol Physiol 2009; 36: 32-39.

19 Dou L, Zhao T, Wang L, Huang X, Jiao J, Gao D, Zhang H, Shen T, Man Y, Wang S, Li J: miR-200s contribute to interleukin-6 (IL-6)-induced insulin resistance in hepatocytes. J Biol Chem 2013;288:22596-22606.

20 Lee YH, Na HS, Jeong SY, Jeong SH, Park HR, Chung J: Comparison of inflammatory microRNA expression in healthy and periodontitis tissues. Biocell 2011;35:43-49.

21 Wang M, Li C, Yu B, Su L, Li J, Ju J, Yu Y, Gu Q, Zhu Z, Liu B: Overexpressed miR-301a promotes cell proliferation and invasion by targeting RUNX3 in gastric cancer. J Gastroenterol 2013;48:1023-1033.

22 Ma F, Zhang J, Zhong L, Wang L, Liu Y, Wang Y, Peng L, Guo B: Upregulated microRNA-301a in breast cancer promotes tumor metastasis by targeting PTEN and activating Wnt/beta-catenin signaling. Gene 2014;535:191-197.

23 Lu Z, Li Y, Takwi A, Li B, Zhang J, Conklin DJ, Young KH, Martin R, Li Y: miR-301a as an NF-kappaB activator in pancreatic cancer cells. EMBO J 2011;30:57-67.

24 Panguluri SK, Tur J, Chapalamadugu KC, Katnik C, Cuevas J, Tipparaju SM: MicroRNA-301a mediated regulation of Kv4.2 in diabetes: identification of key modulators. PLoS One 2013;8:60545.

25 Wu L, Zhao Q, Zhu X, Peng M, Jia C, Wu W, Zheng J, Wu XZ: A novel function of microRNA let-7d in regulation of galectin-3 expression in attention deficit hyperactivity disorder rat brain. Brain Pathol 2010;20:10421054.

26 Gao D, Nong S, Huang X, Lu Y, Zhao H, Lin Y, Man Y, Wang S, Yang J, Li J: The effects of palmitate on hepatic insulin resistance are mediated by NADPH Oxidase 3-derived reactive oxygen species through JNK and p38MAPK pathways. J Biol Chem 2010;285:29965-29973.

27 O'Neill CM, Lu C, Corbin KL, Sharma PR, Dula SB, Carter JD, Ramadan JW, Xin W, Lee JK, Nunemaker CS: Circulating levels of IL-1B+IL-6 cause ER stress and dysfunction in islets from prediabetic male mice. Endocrinology 2013;154:3077-3088.

28 Guo J, Li M, Meng X, Sui J, Dou L, Tang W, Huang X, Man Y, Wang S, Li J: MiR-291b-3p Induces Apoptosis in Liver Cell Line NCTC1469 by Reducing the Level of RNA-binding Protein HuR. Cell Physiol Biochem 2014;33:810-822.

29 Gupta A, Dey CS: PTEN, a widely known negative regulator of insulin/PI3K signaling, positively regulates neuronal insulin resistance. Mol Biol Cell 2012;23:3882-3898. 